\title{
The Meaning of Culture from a Human Rights Approach: The Mandate of the UN Special Rapporteur in the Field of Cultural Rights
}

\begin{abstract}
Beatriz Barreiro Carril (BB): We are very grateful to Mylène and Johanne for this conversation for the "Santander Art and Culture Law Review" concerning some crucial, complex issues surrounding the mandate of the UN Special Rapporteur in the field of cultural rights. ${ }^{1}$ Many interesting questions can be posed in this context: How the mandate deals with the definitions of culture or identity concerning indigenous peoples
\end{abstract}

\footnotetext{
* Mylène Bidault holds a doctorate in law (University of Paris X Nanterre, University of Geneva). She is a member of the Fribourg Group - Interdisciplinary Institute of Ethics and Human Rights (currently Observatory of Diversity and Cultural Rights) at the University of Fribourg (Switzerland). She participated in the drafting and dissemination of the Fribourg Declaration on Cultural Rights (2007), which has greatly contributed to international reflection and debate on this issue. Since 2001, Mylène has been an official at the Office of the United Nations High Commissioner for Human Rights in support of the special procedure in the field of cultural rights.
}

** Johanne Bouchard is an anthropologist, trained in Canada and Switzerland. In 2008, she joined the Fribourg Group - Interdisciplinary Institute of Ethics and Human Rights (currently Observatory of Diversity and Cultural Rights) at the University of Fribourg (Switzerland) as a scientific collaborator. Since 2015, she has worked for the Office of the United Nations High Commissioner for Human Rights in support of the special procedure in the field of cultural rights.

The views expressed by both Mylène and Johanne in this interview are their own personal opinions, which do not necessarily reflect the views of the Office of the High Commissioner for Human Rights.

*** Beatriz Barreiro Carril is Lecturer of International Law at the Rey Juan Carlos University, Madrid (Spain) (orcid.org/0000-0002-3363-059X).

1 The mandate was held until 2015 by Farida Shaheed, and since then by Karima Bennoune. 


\section{INTERVIEWS}

Mylène Bidault and Johanne Bouchard talk to Beatriz Barreiro Carril

in the case of individual or collective complaints? To what extent are anthropologists-advisers necessary in those cases and what would be their influence? What are the advantages for an indigenous group of a complaint before the mandate in comparison with the introduction of such a complaint before Special Rapporteur on the rights of indigenous peoples? Are we facing a trend of indigenous peoples to culturalize their demands, in particular taking into account the difficulties and limits for invoking self-determination?

In addition to the above, and as Johanne pointed out, there is the need to think about the added value of defining the right to take part in cultural life in a universal manner, and not just in the context of minorities and intellectual property. Finally, other important questions concern the interaction needed between this mandate and that of the UN Special Rapporteur on indigenous peoples and the issues related with the intentional destruction of indigenous peoples' cultural heritage. Below is a transcript of what Johanne and Mylène have offered.

\section{BB: How does the Independent Expert ${ }^{2}$ on Cultural Rights deal with the definitions of culture or identities for indigenous peoples in the case of communications?}

Mylène Bidault (MB): I do not think there is a specific definition of culture for indigenous peoples. The mandate is an approach per rights, and not an approach per groups, which makes a big difference. In addition, Farida Shaheed said in her first report that she would not try to define "culture", as there are so many definitions and controversies about this term. She adopted a working definition of cultural rights. In fact, as you may remember, everything is in this first report, which really shaped the mandate for years afterwards, including on how identity is considered. The approach, which is similar to that of the Fribourg Group and the Fribourg Declaration on Cultural Rights - a document that served as a great source of inspiration for the mandate - is not to consider culture as characterizing one group as an entity, as is done at UNESCO since the 1982 Mexico City Declaration on Cultural Policies. This approach puts the focus on people. Cultural rights are the rights of people, alone or in community with others, to define and express their own identity and humanity through, inter alia, values, beliefs, convictions, languages, knowledge and the arts, institutions, and ways of life. That also applies

2 The mandate started as that of an Independent Expert for the three first years, but then was transformed into a Special Rapporteur, and now the common practice is to refer, for the sake of practicality, to the Special Rapporteur (SR) even if we go back to 2009. Therefore, SR is the term most often used in this conversation. 
to indigenous peoples. Of course there is a collective, and the SR never denied there was a collective, but there is a huge diversity within the collective and you cannot lose sight of that if you have an approach through cultural rights. This is a change of paradigm. The difficulty is to take into consideration at the same time individual rights and the collective dimension of the group, because of course to defend your rights, to exercise your rights in the field of culture, you need the collective, but not at any price. And I would never say that there is a specific approach to indigenous cultural rights. The approach is that of cultural rights for all, including for indigenous peoples.

Johanne Bouchard (JB): Basically, the idea of self-determination in this case is understood as every person having a right to self-determine and to identify oneself by referring to many resources. This is not a prerogative just of groups, exactly because of the diversity present within each group. So, whereas self-determination before was used mainly for groups and especially by indigenous peoples, the perspective of cultural rights from the 1980s has understood self-determination as being for everyone, and not just for people belonging to certain groups. Therefore, self-determination is also the right to determine oneself to belong to one or more than one group, and not just be inside of one or be considered as being inside of one. But your question was also about looking into complaints. Mylène, can you think of a communication or a complaint that we would have received where people have claimed to have been denied their right either to self-identify or to self-determine themselves? I do not remember this issue being particularly something that was raised within the communications.

MB: No, but this has been discussed by the Special Rapporteur during country visits, for example when she visited Cyprus. ${ }^{3}$ In addition, the working definition of culture and of identities used by the mandate remains the same, whether for communications or writing thematic reports.

BB: I see, the Special Rapporteur is concerned about the capacity of each individual to participate in the definition of what is the "culture" of the group, about the individual side of participation in the definition of cultural life. The concern of the $\mathbf{2 0 1 6}$ annual report of the mandate about the uses and the meaning of the term "communities" which neglects - or even may violate - the individual side of cultural rights is along this line. I could imagine a hypothetical case before the mandate where a group demands something as being the "culture" of the group, while inside this group some people may be contesting such a definition. 


\section{INTERVIEWS}

Mylène Bidault and Johanne Bouchard talk to Beatriz Barreiro Carril

MB: Yes, you may well imagine this, and in fact that is an underlying question for a great number of issues. For example, when an artist is threatened because of his or her works, this may be because in the end, while the government considers that the controversial works in question are not "culture" or are an attempt to undermine "traditional culture", the artist may consider that: "yes indeed this is culture; living culture with new developments and questions". Both do not have the same understanding of what their shared culture is. I would like to add something in the context of the communication procedure, to which you pay particular attention. As you mentioned at the beginning, the mandate's mechanism is not an adjudication procedure, but a quasi-adjudication one. That means that there is also no procedure for complaints' admissibility. The SR does not have to justify why she takes or doesn't take action on specific complaints. In any case, we would have no capacity to manage an admissibility procedure, due to the number of complaints received each year by special procedures and the limited human resources at the Office of the High Commissioner for Human Rights. There is of course a policy and a strategy of the Rapporteur for deciding which cases she will take up. But it depends on what is urgent in terms of possible harm being done to people, on what seems emblematic, and on what is new and deserves her interest. Conversely however, some claims may ask questions which are too new or too soon for the SR to respond to. There is a grey area, including on what is culture or not. I'll give you an example: Is there a specific cultural relationship of people with corn in certain countries, particularly in Latin America? I remember some years ago we received a complaint claiming that corn with GMOs (genetically modified organisms) was in contradiction to cultural rights, as they jeopardized a plant with strong cultural dimensions. Was this an authentic claim? Or perhaps not an authentic claim, meaning a simple argument designed to ensure an action from the SR? If you visit a Diego Rivera exhibit, you can see corn everywhere, in many paintings. Corn is a symbol - it clearly means something. However in the claim people did not sufficiently explain what they meant. The groups bringing a complaint before the mandate need to make their case. Communication is highly important at this point. It is not for the mandate to decide what is culture and what is not culture; it is for the people to decide about this and to explain it clearly in their complaints. At the same time the mandate does not have to accept everything that victims claim to be culture; the mandate needs to remain critical. This is a difficult exercise, but the door remains open for taking into consideration cultural practices having a strong meaning for the people who introduce the complaint, while meaning nothing to someone else. Victims must include additional 
and very specific documentation explaining, for example, why corn is so important from a cultural point of view. The mandate must at the same time remain very cautious about "forum shopping", when people use culture as a catchall in cases where, in reality, there is not a cultural base for their pretensions.

JB: I completely agree with what Mylène just said. On the one side, we need to have better communication so that the mandate can understand why certain practices are important and what they mean. And on the other side, our job in the mandate is also to keep in mind that it is not enough that someone has a cultural attachment to a practice to make such a practice worthy of cultural protection. We always take human rights as the basic tool on which we base our analysis, to decide if a practice conveys dignity and respects all other rights. These are discussions that also need to happen within communities, to decide whether or not, and to which extent, practices that violate other human rights are practices they want to continue, to convey, to keep up, and to transmit to future generations. The indivisibility of human rights is essential in this context.

BB: Your work within the mandate is fascinating because you are dealing with an issue which is dynamic - culture - while the Law has a tendency to be static. So, I think that the fact that the communication mechanism is quasi-judicial instead of judicial is really very helpful. Because dealing with culture is very difficult for judicial bodies. The outstanding lawyer and anthropologist Marie Claire Foblets said that courts are not very often the best place to deal with culture. You are in a privileged position, by, as you mentioned, having the capacity of cautiously deciding which cases you will take action on. I think this is essential for contributing to the progress of cultural rights while maintaining a dynamic understanding.

MB: I completely agree with you, although I believe that the adoption of the Optional Protocol to the International Covenant on Economic, Social and Cultural Rights (ICESCR) is a wonderful tool, which has the potential to enable great advances in the field of cultural rights. Sure we have more flexibility than a court. Courts like the European Court of Human Rights (ECtHR) are facing great difficulties in determining what, for instance, religious practices are. The ECtHR considered that a religious practice is a practice that is intimately linked to the personal convictions of the person and constitutes aspects of a religion or a conviction in a form generally recognized as such. There is the need to take into consideration the narrative of the victim, but representatives of the group may also be consulted by the ECtHR. How are those representatives chosen? Why should one representative's voice prevail over that of the claimant? These are difficult 


\section{INTERVIEWS}

Mylène Bidault and Johanne Bouchard talk to Beatriz Barreiro Carril

and crucial issues, in particular for women's rights. Surely, it is very difficult to determine if a practice is "generally considered as being cultural". The voices of the claimant(s) are crucial, and they need to be in a position to explain to what extent a practice carries meanings and values, and what is a manifestation of their own worldviews.

JB: I think that this relates to your question about the need of the UN mechanism to have anthropologists as advisers, so as to be able to decide upon certain questions. We have the advantage that the first Special Rapporteur in the field of cultural rights was coming from Sociology, so she had a lot of elements and a lot of tools to take on these questions. My personal experience is that a lot of anthropologists are, sadly enough, afraid of anything that is normative and will go into relativism very quickly. I think that here is where fortunately the protection of the whole system of human rights - which does not allow everything - is really useful. Also, human rights mechanisms need to show more sensitivity to cultural issues. One good way to achieve that would be to include, apart from lawyers, also experts from other disciplines in human rights mechanisms. On the other hand, indigenous peoples' mechanisms could have a stronger approach to the human rights of each person, which would give them additional tools to deal with problems that sometimes arise within communities. This approach can be very useful concerning the questions Mylène was referring to, such as who represents whom; how this is decided; who decides which practices are going to be taken forward; who has the right to define the contours of what makes up the "we" and when you can exclude somebody from that "we".

BB: You are an anthropologist yourself, and Mylène, you are a lawyer. I am very glad to have this interdisciplinary conversation between Law and Anthropology. These kinds of conversations are now more and more common, right? I think Mylène is one of the very first lawyers to be open to other disciplines which are important for cultural rights. Moving to another question, did you see, within the framework of the complaints system, cases where culture is invoked in violation of women rights?

MB: There are many cases where culture is invoked to justify violations of human rights, in particular those of women, and I invite all to read the latest work done by the SR Karima Bennoune on these issues. Those cases often go first to the mechanisms dealing with women's rights, who then may ask the SR on cultural rights to join the communication letters sent to Governments. 
Culture may also be invoked to justify violations of... cultural rights, and there are areas still unexplored, concerning for example access to cultural heritage. Many cultural sites or specific cultural practices are prohibited for women. In other cases, culture is invoked to justify violations of human rights more generally, and not only those of women nor always in the same usual geographical areas. I would like to mention as an example the "Black Pete" case, when the mandate received complaints by minority groups from the Netherlands claiming that the Black Pete celebrations were discriminatory against people of African descent. Proposals in the country to list this tradition as a UNESCO Cultural Heritage were being made at the time. Action taken by several special rapporteurs asking the Government to clarify the matter sparked an enormous controversy and made headlines everywhere. People were shocked that the UN could question a celebration in the Netherlands. But the positive side is that the action taken by special procedures sparked the debate in the country, which I hope is still going on, and raised the awareness of citizens about some problematic aspects of the celebrations. These issues are very complex: I don't think that a practice has to be ignored or disregarded just because it has a discriminatory aspect in cases where it has many other values deserving protection from a cultural rights' perspective. However aspects of a practice that are not in conformity with human rights standards need to be addressed. It is clear that some practices are manifestly unacceptable. But many practices are more complex, including access to sites. The reasons, histories, and meanings of the practice and its consequences for women need to be taken into account and discussed. It is important to consider and promote a practice in a way that is respectful of human rights, including those of women. This is also true for indigenous peoples, who are not always willing to have a conversation about these issues. The adjudication mechanism is not always an easy and effective mechanism in these kinds of cases. The objective is to help people to improve their quality of life by using their cultural identities as empowering tools, which of course may be accompanied by an invitation to introduce changes to their practices when necessary.

JB: This relates to your question about the advantages of one mechanism (the mandate on cultural rights) over another (the mandate on indigenous peoples). I think that part of the response can be found in what Mylène said. If you look into the communications that the Special Rapporteur on the rights of indigenous peoples and other similar mechanisms have written, most of them adopt the perspective of non-discrimination against a specific group. The mandate on cultural rights 


\section{INTERVIEWS}

Mylène Bidault and Johanne Bouchard talk to Beatriz Barreiro Carril

is concerned about the space available for the diversity of ways of life, of meanings, of heritage in relation to the whole society. Indigenous peoples are therefore one element in the variety of peoples forming the whole society. We do not adopt a discrimination angle. We focus instead on the question of what space, what conditions for the diversity of ways of life, practices, meanings, and values are available for people which would allow them to have the real possibility to choose what is important for them, what they want to keep, what they maybe want to amend. And, again, this is where the individual aspect is at the fore.

MB: What Johanne just said brings us back to the complex issue of representation. I am very respectful of the mechanisms indigenous peoples have created in terms of leadership and representation. They have their leaders...

JB: their dialogues...

MB: ... their own structures, their decision-making procedures, etc. When an indigenous people - and sometimes they do this - specify for instance the names of their representatives and the date of their election when submitting a complaint to the SR mandate, we must respect such internal procedures. But at the same time I think that the mandate needs to pay attention to possible discrimination within the group, in terms of who may be excluded from decision making. This is an interesting way of starting a conversation with indigenous groups, as well as to encourage them to do that within the group. These are always case-by-case issues. I remember a specific situation once in the USA when I asked a specific person what was his quality role within the group to request what he was requesting - he was claiming that the refusal to build a monument was a violation of the cultural rights of indigenous peoples - and who he was representing. I never received any answer and I suspect there was no collective behind the request. If the individual aspect is essential for cultural rights, as we are saying in this conversation, the collective aspects are also important.

\section{BB: Yes, I see, Johanne, do you want to say something concerning this?}

JB: The Special Rapporteur presented a report to the General Assembly on the impact of fundamentalism and extremism on the cultural rights of women. ${ }^{4}$ Many of the issues we have been talking about have been raised in the contributions we have received. This is not to say that all groups or communities are extremists

4 This report on "the impact of fundamentalism and extremism on the cultural rights of women" (A/72/155) was presented to the General Assembly on July 2017. 
of course, but there may be some practices or norms that exist inside some of these groups that tend to diminish the space for women to fully take part and to be considered as voices of equal value inside of the decision-making process.

\section{BB: Thank you very much.}

MB: I would like to say something concerning the culturalization of the demands, which you raised in your introduction. This is a trend, but I think that international law itself has forced peoples to do that. This was true for minorities (who under the ICCPR only had recognized rights in the fields of language, religion, and culture). It is also true for indigenous peoples: what other means do they have? They are not generally listened to if they invoke the right to self-determination, which is the primary right for them. As a consequence, they have to find their own means. And I would say more: The demands that minorities and indigenous peoples have formulated for decades have enormously contributed to the understanding of what culture is, also in relation of our "non-indigenous" societies. They have taught us highly important lessons, relating in particular to an holistic approach of what culture is, our relationship to the environment and in particular to animals, our place in the world. Consequently, I am not so critical about the trend toward culturalization, also because as we discussed earlier it is for people to decide and explain what is culture for them. I think that it is a very complex and fascinating issue. It also gives us a lot of food for thought for ourselves.

JB: I think that this fits nicely in the question you proposed for this conversation on the interaction between the mechanisms, which is starting to be more frequent. But I think there are a lot of things to be done by the different mechanisms in order for them to really complement each other. One of the criticisms we are used to hearing is that we should avoid any overlap of the mandates. I tend rather to say that we need those overlaps all the more, because there is a need for some kind of coherence inside of the system we are in. That does not necessarily mean to work from the same angle, but to work in the same direction and integrate the cultural rights' perspective and the cultural dimension along with other rights. This is definitely something I think needs to be developed more in the future, and I hope that the mandate will contribute to this. As regards cultural heritage and the destruction of cultural heritage - topics you mentioned at the beginning of our conversation - this is definitely a door that is open. There was a meeting organized in 2016. The Special Rapporteur in the field of cultural rights took part in the Indigenous Peoples Forum in New York. There was another discussion about peace and conflict, where the international community looked into the intention- 


\section{INTERVIEWS}

Mylène Bidault and Johanne Bouchard talk to Beatriz Barreiro Carril

al destruction of cultural heritage in the context of the International Criminal Court. But what about times of peace? I think this is a big issue that needs to be raised, and one about which indigenous peoples and minorities have been trying to warn for years. This is extremely important, because it is also opening the door for other people to start claiming that - even if they do not belong to an indigenous people - they considered that Medina, an old city, for instance, belongs to their heritage, no matter if it is or is not listed in a UNESCO list or similar list. This is essential for improving the consciousness of what culture represents for human dignity. 